\title{
ANALYSIS
}

\section{The antibiotic course has had its day}

With little evidence that failing to complete a prescribed antibiotic course contributes to antibiotic resistance, it's time for policy makers, educators, and doctors to drop this message, argue Martin Llewelyn and colleagues

\author{
Martin J Llewelyn professor of infectious diseases ${ }^{12}$, Jennifer M Fitzpatrick specialist registrar in \\ infection $^{2}$, Elizabeth Darwin project manager ${ }^{3}$, SarahTonkin-Crine health psychologist ${ }^{4}$, Cliff Gorton \\ retired building surveyor ${ }^{5}$, John Paul consultant in microbiology ${ }^{6}$, Tim E A Peto professor of infectious \\ diseases ${ }^{7}$, Lucy Yardley professor of health psychology ${ }^{8}$, Susan Hopkins consultant in infectious \\ diseases and microbiology ${ }^{9}$, Ann Sarah Walker professor of medical statistics and epidemiology ${ }^{3}$
}

\begin{abstract}
'Department of Global Health and Infection, Brighton and Sussex Medical School, Falmer, BN1 9PS, UK; ${ }^{2}$ Department of Microbiology and Infection, Brighton and Sussex University Hospitals NHS Trust, Brighton, UK ; ${ }^{3}$ Nuffield Department of Medicine, University of Oxford, UK; ${ }^{4}$ Nuffield Department of Primary Care Health Sciences, Oxford, UK; ${ }^{5} \mathrm{Oxford}$, UK; ${ }^{6}$ Public Health England, Royal Sussex County Hospital, Brighton, UK; ${ }^{7}$ Oxford Biomedical Research Centre, Oxford, UK; ${ }^{8}$ Faculty of Human and Social Sciences, University of Southampton, UK ; ${ }^{9}$ Royal Free London NHS Foundation Trust, London, UK ; Correspondence to: M Llewelyn M.J.Llewelyn@bsms.ac.uk
\end{abstract}

Antibiotics are vital to modern medicine and antibiotic resistance is a global, urgent threat to human health. The relation between antibiotic exposure and antibiotic resistance is unambiguous both at the population level ${ }^{1}$ and in individual patients. ${ }^{2}$ Reducing unnecessary antibiotic use is therefore essential to mitigate antibiotic resistance.

Avoiding overuse requires healthcare professionals and the public to be well informed about antibiotic treatment, as set out in the first objective of the World Health Organization Global Action Plan. ${ }^{3}$ Public communication about antibiotics often emphasises that patients who fail to complete prescribed antibiotic courses put themselves and others at risk of antibiotic resistance. For example, in materials supporting Antibiotic Awareness Week 2016 WHO advised patients to "always complete the full prescription, even if you feel better, because stopping treatment early promotes the growth of drug-resistant bacteria." ${ }^{4}$ Similar advice appears in national campaigns in Australia, ${ }^{5}$ Canada, ${ }^{6}$ the United States, ${ }^{7}$ and Europe. ${ }^{8}$ And in the United Kingdom it is included as fact in the curriculum for secondary school children. ${ }^{9}$

However, the idea that stopping antibiotic treatment early encourages antibiotic resistance is not supported by evidence, while taking antibiotics for longer than necessary increases the risk of resistance. Without explicitly contradicting previous advice, current public information materials from the US Centers for Disease Control and Prevention (CDC) and Public Health England have replaced "complete the course" with messages advocating taking antibiotics "exactly as prescribed." ${ }^{11} \mathrm{We}$ explore the evidence for antibiotic duration, clinical effectiveness, and resistance, and encourage policy makers, educators, and doctors to stop advocating "complete the course" when communicating with the public. Further, they should publicly and actively state that this was not evidence-based and is incorrect.

\section{Origins of the idea}

Concern that giving too little antibiotic treatment could select for antibiotic resistance can be traced back to the dawn of the antibiotic era. When Howard Florey's team treated Albert Alexander's staphylococcal sepsis with penicillin in 1941 they eked out all the penicillin they had (around $4 \mathrm{~g}$, less than one day's worth with modern dosing) over four days by repeatedly recovering the drug from his urine. When the drug ran out, the clinical improvement they had noted reversed and he subsequently succumbed to his infection. ${ }^{12}$ There was no evidence that this was because of resistance, but the experience may have planted the idea that prolonged therapy was needed to avoid treatment failure.

Fleming's early work showed that sensitive bacteria could be "acclimatised" to penicillin in the laboratory. ${ }^{13}$ In his 1945 Nobel prize acceptance speech, Fleming painted a vivid clinical vignette in which an imagined patient with a streptococcal throat infection who takes insufficient penicillin, transmits the infection-now in resistant form-to his wife, and is thus responsible for her subsequent death from antibiotic resistant disease. ${ }^{14}$ Fleming advised, "If you use penicillin, use enough!" Ironically, Streptococcus pyogenes has never developed resistance to penicillin, and we now know that for most forms of antibiotic resistance that currently threaten patients, selection of resistance in the bacteria being treated is of limited importance.

\section{Antibiotic treatment drives resistance}

The scenario envisaged by Fleming was of target selected resistance (box 1). Infections typically begin when a small 
population of microorganisms gain access to the host and replicate. Genetic mutations conferring antibiotic resistance may arise spontaneously during replication and be selected for during treatment. Target selected resistance can occur with inadequate antimicrobial dosing or with monotherapy for infections for which spontaneous resistant mutations arise on treatment, such as tuberculosis, gonorrhoea, and HIV.

Early trials of tuberculosis treatment showed resistance emerging during monotherapy ${ }^{15}$ and underpin the need for combination therapy for this disease. Transmission of such pathogens during or following inadequate treatment may allow resistant strains to spread from person to person.

However, most of the bacterial species now posing the greatest problems do not develop resistance through target selection. The clinical threat comes mainly from species such as Escherichia coli and the so called ESKAPE organisms (Enterococcus faecium, Staphylococcus aureus, Klebsiella pneumoniae, Acinetobacter spp, Pseudomonas spp, Enterobacter spp), which are all found harmlessly in us, on us, or in our environment. They can also act as "opportunistic" pathogens.

When a patient takes antibiotics for any reason, antibiotic sensitive species and strains present among commensal flora on their skin or gut or in the environment are replaced by resistant species and strains ready to cause infection in the future. ${ }^{16}$ This collateral selection (box 1) is the predominant driver of the important forms of antibiotic resistance affecting patients today. The longer the antibiotic exposure these opportunist bacteria are subjected to, the greater the pressure to select for antibiotic resistance. ${ }^{217}$

Importantly for these opportunistic pathogens, resistant strains are transmitted between asymptomatic carriers rather than people with disease. Furthermore, many resistance conferring genes can pass easily between bacterial strains or species. Thus antibiotic selection may drive outbreaks of resistant infections independently of transmission of a specific strain or species. ${ }^{18}$

\section{From fear of undertreatment to harm from overtreatment}

Traditionally, antibiotics are prescribed for recommended durations or courses. Fundamental to the concept of an antibiotic course is the notion that shorter treatment will be inferior. There is, however, little evidence that currently recommended durations are minimums, below which patients will be at increased risk of treatment failure.

Historically, antibiotic courses were set by precedent, driven by fear of undertreatment, with less concern about overuse. For many indications, recommended durations have decreased as evidence of similar clinical outcomes with shorter courses has been generated (table $1 \Downarrow$ ). However, the picture is patchy and complicated by comparisons of new and established agents that may have different pharmacological properties (eg, long acting macrolides versus short acting penicillins).

For most indications, studies to identify the minimum effective treatment duration simply have not been performed. ${ }^{28}$ For example, pyelonephritis has historically been treated for two weeks. Trials have shown that shorter courses of quinolones are effective (seven days for ciprofloxacin ${ }^{23}$ and five days for levofloxacin ${ }^{24}$ ), but no such data exist for $\beta$-lactams, which are the main antibiotic class used. Current international guidelines recommend 10-14 days' treatment with $\beta$-lactams, based purely on absence of data for shorter courses. ${ }^{29}$

Shorter duration of treatment has been shown to reduce clinical efficacy in a few cases. A notable example is otitis media, where five days' treatment is associated with a lower clinical cure rate $(66 \%)$ than 10 days $(84 \%)$ in children under 2 years. ${ }^{19}$ Even in this situation though, differences relate to prolongation of symptoms not treatment failure, disease recurrence, or selection for resistant pathogens.

For the opportunist pathogens for which antimicrobial resistance poses the greatest threat, no clinical trials have shown increased risk of resistance among patients taking shorter treatments.

The key argument for changing how we discuss antibiotic courses with patients is that shorter treatment is clearly better for individual patients. Not only does an individual patient's risk of resistant infection depend on their previous antibiotic exposure ${ }^{217}$ but reducing that exposure by shorter treatment is associated with reduced risk of resistant infection and better clinical outcome. In hospital acquired pneumonia, for example, randomised controlled trial data indicate that short treatment strategies have equivalent clinical outcomes to longer courses and are associated with lower rates of infection recurrence and antibiotic resistance..$^{2526}$

\section{Is the concept of an antibiotic course still valid?}

The concept of an antibiotic course ignores the fact that patients may respond differently to the same antibiotic, depending on diverse patient and disease factors. Currently, we largely ignore this fact and instead make indication specific recommendations for antibiotic duration that are based on poor evidence. This situation is changing in hospital practice, where biomarkers of treatment response such as procalcitonin can guide when to stop antibiotic treatment. ${ }^{30}$ Outside hospital, where repeated testing may not be feasible, patients might be best advised to stop treatment when they feel better, in direct contradiction of WHO advice. ${ }^{4}$ Of note, a recent clinical trial found that using fever resolution to guide stopping antibiotics in community acquired pneumonia halved the average duration of antibiotic treatment without affecting clinical success. ${ }^{21}$ Further similar studies are needed.

\section{"Complete the course": a barrier to antibiotic conservation}

The fallacious belief that antibiotic courses should always be completed to minimise resistance is likely to be an important barrier to reducing unnecessary antibiotic use in clinical practice and to developing evidence to guide optimal antibiotic use. The idea is deeply embedded, and both doctors and patients currently regard failure to complete a course of antibiotics as irresponsible behaviour. $^{31} 32$

In primary care, strategies have been developed to avoid unnecessary antibiotic courses being started-for example, through enhanced communication training, point-of-care tests, and use of delayed prescriptions. ${ }^{33-35}$ However in secondary care, strategies to reduce overuse aim to change, or ideally stop, antibiotics 48-72 hours after they are started, but these are challenging to implement. ${ }^{36}$ Reasons for this include diagnostic uncertainty and team behaviour, but patients' and healthcare professionals' concerns about the risks of incomplete treatment are likely to contribute. Designing trials of antibiotic sparing treatment is notoriously difficult, ${ }^{37}$ particularly if participants are invited to consent to receiving shortened antibiotic treatment on the basis that this could reduce their risk of antibiotic resistance, when they have been taught from school that it increases this risk. 


\section{Box 1: Selection of antibiotic resistance}

Target selection-For certain "professional" pathogens, such as Mycobacterium tuberculosis, spontaneous resistance conferring mutants may be selected during treatment, can be transmitted before cure is achieved, or can re-emerge after treatment failure. Other professional pathogens where this may apply include HIV, malaria, gonorrhoea, and Salmonella typhi

Collateral selection-Many bacterial species that live harmlessly in the gut, on our skin and mucus membranes, or in the environment can also cause disease as opportunist pathogens. For such organisms, resistance selection occurs predominantly during antibiotic treatment of other infections. Resistance in opportunists may be passed easily to other strains of the same species of bacteria or to different species. Key examples include methicillin resistance in Staphylococcus aureus, extended spectrum $\beta$-lactamase producing Enterobacteriaceae and carbapenem resistance in Klebsiella pneumoniae

\section{What should we advise patients?}

The "complete the course" message has persisted despite not being supported by evidence and previous arguments that it should be replaced. ${ }^{1838}$ One reason it may be so resilient is that it is simple and unambiguous, and the behaviour it advocates is clearly defined and easy to carry out. Nevertheless, there is evidence that, in many situations, stopping antibiotics sooner is a safe and effective way to reduce antibiotic overuse. Daily review of the continued need for antibiotics is a cornerstone of antibiotic stewardship in hospitals, ${ }^{39}$ but in primary care, where $85 \%$ of antibiotic prescriptions are written, no such ongoing assessment is attempted.

There are reasons to be optimistic that the public will accept that completing the course to prevent resistance is wrong if the medical profession openly acknowledges that this is so, rather than simply substituting subtle alternatives such as "exactly as prescribed." Completing the course goes against one of the most fundamental and widespread medication beliefs people have, which is that we should take as little medication as necessary. ${ }^{40}$ Concerted and consistent efforts have successfully educated the public that antibiotics do not treat viral infections, for example. Research is needed to determine the most appropriate simple alternative messages, such as stop when you feel better. Until then, public education about antibiotics should highlight the fact that antibiotic resistance is primarily the result of antibiotic overuse and is not prevented by completing a course. The public should be encouraged to recognise that antibiotics are a precious and finite natural resource that should be conserved. This will allow patient centred decision making about antibiotic treatment, where patients and doctors can balance confidence that a complete and lasting cure will be achieved against a desire to minimise antibiotic exposure unimpeded by the spurious concern that shorter treatment will cause antibiotic resistance.

Contributors and sources: LY, MJL, TEAP, SH, and ASW are investigators on an on an NIHR Programme Grant for Applied Research (PGfAR) called ARK-hospital, which aims to reduce antibiotic overuse in hospitals through clinical review of antibiotic prescriptions [RP-PG-0514-20015]. ASW, STC, TEAP, and SH are investigators in the NIHR Health Protection Research Unit (NIHR HPRU) in healthcare associated infections and antimicrobial resistance at Oxford University in partnership with Public Health England (PHE) [grant HPRU-2012-10041]. CG is a retired building surveyor. ED is a project manager for ARK and the HPRU. JP is Public Health England regional microbiologist for the south east. The article is based on published good quality randomised clinical trials and observational cohort studies. All authors have contributed to this paper and concur on its content. MJL is guarantor. The views expressed in this publication are those of the authors and not necessarily those of their employers.

Competing interests: We have read and understood BMJ policy on declaration of interests and have no relevant interests to declare.

Goossens H, Ferech M, Vander Stichele R, Elseviers M. ESAC Project Group. Outpatien antibiotic use in Europe and association with resistance: a cross-national database study. Lancet 2005;358:579-87. doi:10.1016/S0140-6736(05)70799-6 pmid:15708101.
2 Costelloe C, Metcalfe C, Lovering A, Mant D, Hay AD. Effect of antibiotic prescribing in primary care on antimicrobial resistance in individual patients: systematic review and meta-analysis. BMJ 2010;358:c2096. doi:10.1136/bmj.c2096. pmid:20483949.

3 World Health Organization. Global action plan on antimicrobial resistance 2015.http:// www.wpro.who.int/entity/drug_resistance/resources/global_action_plan_eng.pdf

4 World Health Organization. How to stop antibiotic resistance? Here's a WHO prescription. 2015. http://www.who.int/mediacentre/commentaries/stop-antibiotic-resistance/en/

5 NPS Medicinewise. Antibiotic resistance: the facts. https://www.nps.org.au/medical-info/ consumer-info/antibiotic-resistance-the-facts

6 National Collaborating Centre for Infectious Diseases. Antibiotic use and resistance: information for patients. https://nccid.ca/antibiotic-awareness/

7 Federal Drugs Administration. Combatting antibiotic resistance. Follow directions for proper use. https://www.fda.gov/ForConsumers/ConsumerUpdates/ucm092810.htm\# follow

8 European Antibiotic Awareness Day. Factsheet for general public. http://ecdc.europa.eu/ en/eaad/antibiotics-get-informed/Pages/get-informed.aspx

9 Assessment and Qualifications Alliance. GCSE biology specification. http://www.aqa.org. uk/subjects/science/gcse/biology-8461

10 Centers for Disease Control. Get smart about antibiotics. What you can do. https://www. cdc.gov/getsmart/community/about/can-do.html

11 UK Government. Antibiotic awareness resources 2016. https://www.gov.uk/government/ collections/european-antibiotic-awareness-day-resources

12 Abraham EP, Chain E, Fletcher CM, et al. Further observations on penicillin. Lance 1941;358:177-89doi:10.1016/S0140-6736(00)72122-2.

13 Fleming A. On the antibacterial action of cultures of a penicillium, with special reference to their use in the isolation of B. influenzae. Br J Exp Pathol 1929:358:226-36.

14 Fleming A. Penicillin. Nobel lecture, 11 Dec 1945.https://www.nobelprize.org/nobel_prizes/ medicine/laureates/1945/fleming-lecture.pdf

15 Medical Research Countil. Streptomycin treatment of pulmonary tuberculosis. Br Med J 1948;358:769-82. doi:10.1136/bmj.2.4582.769 pmid:18890300.

16 Crémieux A-C, Muller-Serieys C, Panhard X, et al. Emergence of resistance in normal human aerobic commensal flora during telithromycin and amoxicillin-clavulanic acid treatments. Antimicrob Agents Chemother 2003;358:2030-5. doi:10.1128/AAC.47.6.2030 2035.2003 pmid:12760893.

17 Lodise TP, Miller CD, Graves J, et al. Clinical prediction tool to identify patients with Pseudomonas aeruginosa respiratory tract infections at greatest risk for multidrug resistance. Antimicrob Agents Chemother 2007;358:417-22. doi:10.1128/AAC.0085106 pmid: 17158943.

18 Sheppard AE, Stoesser N, Wilson DJ, et al. Modernising Medical Microbiology (MMM) Informatics Group. Nested Russian doll-like genetic mobility drives rapid dissemination of the carbapenem resistance gene blaKPC. Antimicrob Agents Chemother 2016;358:3767-78. doi:10.1128/AAC.00464-16 pmid:27067320.

19 Hoberman A, Paradise JL, Rockette HE, et al. Shortened Antimicrobial Treatment for Acute Otitis Media in Young Children. N Engl J Med 2016;358:2446-56. doi:10.1056/ NEJMoa1606043 pmid:28002709.

20 Altamimi S, Khalil A, Khalaiwi KA, Milner RA, Pusic MV, Al Othman MA. Short-term late-generation antibiotics versus longer term penicillin for acute streptococcal pharyngitis in children. Cochrane Database Syst Rev 2012;8:CD004872.pmid:22895944.

21 Uranga A, España PP, Bilbao A, et al. Duration of antibiotic treatment in community-acquired pneumonia: a multicenter randomized clinical trial. JAMA Intern Med 2016;358:1257-65. doi:10.1001/jamainternmed.2016.3633. pmid:27455166.

22 Hepburn MJ, Dooley DP, Skidmore PJ, Ellis MW, Starnes WF, Hasewinkle WC Comparison of short-course ( 5 days) and standard (10 days) treatment for uncomplicated cellulitis. Arch Intern Med 2004;358:1669-74. doi:10.1001/archinte.164.15.1669 pmid: 15302637.

23 Sandberg T, Skoog G, Hermansson AB, et al. Ciprofloxacin for 7 days versus 14 days in women with acute pyelonephritis: a randomised, open-label and double-blind, placebo-controlled, non-inferiority trial. Lancet 2012;358:484-90. doi:10.1016/S0140-6736 12)60608-4 pmid:22726802.

24 Peterson J, Kaul S, Khashab M, Fisher AC, Kahn JB. A double-blind, randomized comparison of levofloxacin $750 \mathrm{mg}$ once-daily for five days with ciprofloxacin $400 / 500 \mathrm{mg}$ twice-daily for 10 days for the treatment of complicated urinary tract infections and acute pyelonephritis. Urology 2008:358:17-22. doi:10.1016/j.urology.2007.09.002 pmid:18242357.

25 Chastre J, Wolff M, Fagon JY, et al. PneumA Trial Group. Comparison of 8 vs 15 days of antibiotic therapy for ventilator-associated pneumonia in adults: a randomized trial. JAMA 2003;358:2588-98. doi:10.1001/jama.290.19.2588 pmid:14625336.

26 Singh N, Rogers P, Atwood CW, Wagener MM, Yu VL. Short-course empiric antibiotic therapy for patients with pulmonary infiltrates in the intensive care unit. A proposed solution for indiscriminate antibiotic prescription. Am J Respir Crit Care Med 2000;358:505-11. doi:10.1164/ajrccm.162.2.9909095 pmid:10934078.

27 Sawyer RG, Claridge JA, Nathens AB, et al. Trial of short-course antimicrobial therapy for intraabdominal infection. N Engl J Med 2015;358:1996-2005. doi:10.1056/ NEJMoa1411162 pmid:25992746.

28 Spellberg B. The new antibiotic mantra- "shorter is better". JAMA Intern Med 2016;358:1254-5. doi:10.1001/jamainternmed.2016.3646 pmid:27455385.

29 Gupta K, Hooton TM, Naber KG, et al. Infectious Diseases Society of America European Society for Microbiology and Infectious Diseases. International clinical practice guidelines for the treatment of acute uncomplicated cystitis and pyelonephritis in women: A 2010 update by the Infectious Diseases Society of America and the European Society for Microbiology and Infectious Diseases. Clin Infect Dis 2011;358:e103-20. doi:10.1093/cid/ ciq257 pmid:21292654. 


\section{Key messages}

Patients are put at unnecessary risk from antibiotic resistance when treatment is given for longer than necessary, not when it is stopped early

For common bacterial infections no evidence exists that stopping antibiotic treatment early increases a patient's risk of resistant infection Antibiotics are a precious and finite natural resource which should be conserved by tailoring treatment duration for individual patients Clinical trials are required to determine the most effective strategies for optimising duration of antibiotic treatment

30 Schuetz P, Chiappa V Briel M, Greenwald UL. Procalcitonin algorithms for antibiotic therapy decisions: a systematic review of randomized controlled trials and recommendations for clinical algorithms. Arch Intern Med 2011;358:1322-31. doi:10.1001/ archinternmed.2011.318 pmid:21824946.

31 Brookes-Howell L, Elwyn G, Hood K, et al. 'The body gets used to them': patients' interpretations of antibiotic resistance and the implications for containment strategies. $J$ Gen Intern Med 2012;358:766-72. doi:10.1007/s11606-011-1916-1 pmid:22065334.

32 McCullough AR, Parekh S, Rathbone J, Del Mar CB, Hoffmann TC. A systematic review of the public's knowledge and beliefs about antibiotic resistance. J Antimicrob Chemother 2016;358:27-33. doi:10.1093/jac/dkv310 pmid:26459555.

33 Little P, Moore M, Kelly J, et al. PIPS Investigators. Delayed antibiotic prescribing strategies for respiratory tract infections in primary care: pragmatic, factorial, randomised controlled trial. BMJ 2014:358:g1606. doi:10.1136/bmj.g1606 pmid:24603565.

34 Little P, Stuart B, Francis N, et al. GRACE consortium. Effects of internet-based training on antibiotic prescribing rates for acute respiratory-tract infections: a multinational, cluster randomised, factorial, controlled trial. Lancet 2013;358:1175-82. doi:10.1016/S0140-6736( 13)60994-0 pmid:23915885

35 Butler CC, Simpson SA, Dunstan F, et al. Effectiveness of multifaceted educational programme to reduce antibiotic dispensing in primary care: practice based randomised controlled trial. BMJ 2012;358:d8173. doi:10.1136/bmj.d8173 pmid:22302780.
36 Lewelyn MJ, Hand K Hopkins S, Walker AS. Antibiotic policies in acute English NHS trusts: implementation of "start smart-then focus" and relationship with Clostridium difficile infection rates. J Antimicrob Chemother 2015;358:1230-5.pmid:25538165.

37 Davey P, Brown E, Charani E, et al. Interventions to improve antibiotic prescribing practices for hospital inpatients. Cochrane Database Syst Rev 2013:358.CD003543 pmid.23633313.

38 Lambert HP. Don't keep taking the tablets? Lancet 1999;358:943-5. doi:10.1016/S01406736(99)01139-3 pmid:10489971.

39 UK Government. Start smart then focus. Antimicrobial stewardship toolkit for English hospitals. https://www.gov.uk/government/publications/antimicrobial-stewardship-startsmart-then-focus

40 Horne R, Chapman SC, Parham R, Freemantle N, Forbes A, Cooper V. Understanding patients' adherence-related beliefs about medicines prescribed for long-term conditions: a meta-analytic review of the necessity-concerns framework. PLoS One 2013;358:e80633. a meta-analytic review of the necessity-concerns fram
doi:10.1371/journal.pone.0080633 pmid:24312488.

Published by the BMJ Publishing Group Limited. For permission to use (where not already granted under a licence) please go to http://group.bmj.com/group/rights-licensing/ permissions 


\section{Table}

Table 1 | Indications for which duration of antibiotic treatment has been evaluated by randomised controlled trial

\begin{tabular}{|c|c|c|c|c|}
\hline \multirow[t]{2}{*}{ Indication } & \multicolumn{2}{|c|}{ No of days treatment } & \multirow[t]{2}{*}{ Main evidence } & \multirow[t]{2}{*}{ Evidence on resistance } \\
\hline & Standard & Evaluated & & \\
\hline Otitis media ${ }^{19}$ & 10 & 5 & Clinical failure higher with 5 days than 10 days treatment ( 1 trial) & $\begin{array}{l}\text { Similar short term selection of resistance in } \\
\text { nasopharyngeal organisms }\end{array}$ \\
\hline Streptococcal pharyngitis ${ }^{20}$ & 10 & $3-6$ & $\begin{array}{l}\text { Comparable effect of 3-6 days oral antibiotics to } 10 \text { days penicillin } \\
\text { in children with streptococcal throat infection (Cochrane review of } \\
20 \text { studies) }\end{array}$ & Not assessed \\
\hline $\begin{array}{l}\text { Community acquired } \\
\text { pneumonia }^{21}\end{array}$ & $7-10$ & 5 & $\begin{array}{l}\text { Non-inferiority of } 5 \text { day course once afebrile and clinical stability } \\
\text { improving compared with physician guided therapy (median } 10 \\
\text { days) for clinical success ( } 1 \text { trial) }\end{array}$ & $\begin{array}{l}\text { Not assessed. } \beta \text {-lactam treatment }>5 \text { days } \\
\text { associated with greater carriage of resistant } \\
S \text { pneumoniae }\end{array}$ \\
\hline Cellulitis $^{22}$ & $7-14$ & 5 & $\begin{array}{l}\text { Non-inferiority of } 5 \text { day course compared with } 10 \text { days for clinical } \\
\text { resolution ( } 1 \text { trial) }\end{array}$ & Not assessed \\
\hline Pyelonephritis ${ }^{2324}$ & 14 & $5-7$ & $\begin{array}{l}\text { Non-inferiority of } 7 v 14 \text { days ciprofloxacin for cure }{ }^{12} \text { and } 5 \text { days } \\
\text { levofloxacin } v 10 \text { days ciprofloxacin for eradication of infection } \\
\text { and clinical cure }\end{array}$ & Not assessed \\
\hline Nosocomial pneumonia ${ }^{2526}$ & $10-15$ & $7-8$ & $\begin{array}{l}\text { Non-inferiority of short course treatment of suspected pneumonia } \\
\text { among critical care patients on ICU mortality and infection } \\
\text { recurrence (multiple trials) }\end{array}$ & $\begin{array}{l}\text { Lower risk of further or resistant infection in } \\
\text { patients receiving shorter duration therapy }\end{array}$ \\
\hline Intra-abdominal sepsis ${ }^{27}$ & $7-14$ & 4 & $\begin{array}{l}\text { Non-inferiority of fixed } 4 \text { day course compared with physician } \\
\text { guided therapy (median } 8 \text { days) for surgical site infection, recurrent } \\
\text { intraabdominal infection, or death ( } 1 \text { trial) }\end{array}$ & $\begin{array}{l}\text { Non-significantly lower rates of } \\
\text { extra-abdominal resistant infection in short } \\
\text { course group }\end{array}$ \\
\hline
\end{tabular}

